\title{
Calcium Pre-Rinse Greatly Increases Overnight Salivary Fluoride after a 228 ppm Fluoride Rinse
}

\author{
G.L. Vogel L.C. Chow C.M. Carey
}

American Dental Association Foundation, Paffenbarger Research Center, Gaithersburg, Md., USA

Key Words

Calcium $\cdot$ Fluoride $\cdot$ Pre-rinse $\cdot$ Saliva

\begin{abstract}
Background: Large increases in salivary fluoride were reported $1 \mathrm{~h}$ after a calcium pre-rinse/NaF rinse. Aims: This study examined the persistence of these increases. Methods: 12 subjects rinsed in the evening with water, with a 228 $\mu \mathrm{g} / \mathrm{g}$ (ppm) F rinse or with $150 \mathrm{mmol} / \mathrm{l}$ calcium lactate followed by a $228 \mu \mathrm{g} / \mathrm{g} F$ rinse. In a second experiment these same patients rinsed with a $912 \mu \mathrm{g} / \mathrm{g} F$ rinse. Saliva samples were obtained the morning after rinsing, centrifuged and the supernatants analyzed. Results: The Ca pre-rinse/228 $\mu \mathrm{g} / \mathrm{g} F$ rinse induced an increase in overnight salivary $\mathrm{F}$ over the $912 \mu \mathrm{g} / \mathrm{g}$ F rinse $(\approx 2.5$ times) and a statistically significant increase over the $228 \mu \mathrm{g} / \mathrm{g}$ F rinse $(\approx 5.5$ times). Conclusions: The results suggest that a Ca pretreatment may increase the cariostatic effect of topical $\mathrm{F}$ agents.
\end{abstract}

Copyright $\odot 2008$ S. Karger AG, Basel

The concentration of fluoride (F) in the oral fluids surrounding the teeth, such as plaque fluid and saliva, greatly influences the rate of enamel de- and remineralization both in vitro [Margolis and Moreno, 1990; ten Cate, 1990] and in vivo [Arends and Christoffersen, 1990; Featherstone, 2000]. Recent studies demonstrate that a calcium (Ca) pre-rinse, given before use of aqueous $\mathrm{NaF}$ rinses, greatly increased the 1-hour F concentration in both cen- trifuged saliva (6-9 times) [Vogel et al., 2006a, b] and plaque fluid (4 times) [Vogel et al., 2008]. Even larger increases (39 times) were reported at the 2007 International Association for Dental Research Meeting with this same F rinse system in studies with whole saliva [Whitford, pers. commun.]. Pessan et al. [2006] however have presented data suggesting that these increases do not persist overnight when the Ca pre-rinse was used with a commercial $\mathrm{F}$ dentifrice. The purpose of this study was to examine overnight salivary $\mathrm{F}$ in which, as in our previous studies, the Ca pre-rinse was used with an aqueous F rinse.

\section{Materials and Methods}

Subject Protocol, Rinse Administration and Sample Collection

Rinse administration and the collection of samples were done with the informed consent of the subjects following protocols reviewed and approved by the appropriate institutional review boards. The 12 subjects ( 8 males, 4 females, age range $24-65$ years, mean age 42.5 years) were screened before participation to ensure good oral health (no signs of neglect or untreated decay) and normal salivary gland function (unstimulated salivary flow rate $>0.2$ $\mathrm{g} / \mathrm{min})$. All subjects lived in an area with fluoridated water (2007

Certain commercial materials and equipment are identified in this paper to specify the experimental procedure. In no instance does such identification imply recommendation or endorsement by the National Institute of Standards and Technology or the American Dental Association Foundation or that the material or the equipment identified is necessarily the best available for the purpose.

\section{KARGER}

๑) 2008 S. Karger AG, Basel

Fax +41613061234 E-Mail karger@karger.ch www.karger.com www.karger.com/cre
Gerald Vogel

American Dental Association Foundation, Paffenbarger Research Center 100 Bureau Drive Stop 8546, National Institute of Standards and Technology Gaithersburg, MD 20899-8546 (USA)

Tel. +1 301975 6821, Fax +1 301963 9143, E-Mail jvogel@nist.gov 
average $\mathrm{F}=0.99 \mu \mathrm{g} / \mathrm{g}$, range $0.49-1.3 \mu \mathrm{g} / \mathrm{g}$ ) and were instructed to use their normal oral hygiene procedures until the day before the study. The day before the study the subjects were instructed to avoid tea (a high F beverage) and to use F-free baking soda powder (Arm \& Hammer, Church \& Dwight, Princeton, N.J., USA) as a dentifrice. They were asked to brush in the morning and to brush again in the evening, about $2 \mathrm{~h}$ before use of the test or control rinses. No food or beverage, gum chewing, or other oral hygiene measures (mouth rinses) were allowed after this brushing until the sample collection the next morning. Each subject rinsed with one of the experimental solutions (or solution combinations): (1) a 228 $\mu \mathrm{g} / \mathrm{g}(\mathrm{ppm}) \mathrm{F}$ rinse $(12 \mathrm{mmol} / \mathrm{l} \mathrm{NaF}),(2)$ a $150 \mathrm{mmol} / \mathrm{l} \mathrm{Ca}$ lactate rinse (Ca lactate pentahydrate, Sigma-Aldrich, St. Louis, Mo., USA), immediately followed by the above F rinse, or (3) a distilled water rinse (control). These rinses were given in a random order, based on the subject's name and a random number sequence. The subjects were not aware of the order of the test materials. At least 5 days separated the use of each rinse. As in previous studies [Vogel, 2006a, b, 2008], all rinses were $20 \mathrm{ml}$ in volume and the rinse times were $1 \mathrm{~min}$. As close as possible to $12 \mathrm{~h}$ after use of these rinses, weighed unstimulated saliva samples then were collected the next morning by expectoration for $2 \mathrm{~min}$ [Vogel et al., 2006a, b]. The samples were then centrifuged $\left(5 \mathrm{~min}, 2^{\circ} \mathrm{C}, 1,466 \mathrm{rad} / \mathrm{s}\right)$ and the recovered clear supernatant diluted ( 9 parts sample with 1 part TISAB III, Thermo-Orion, Shelton, Conn., USA). The diluted samples, and similarly diluted F standards, were analyzed in our laboratory using the inverted electrode apparatus previously described [Vogel et al., 1990]. It should be noted however that an acetone cleaning of the electrode followed by an extensive 'conditioning' [Vogel et al., 1990] of the electrode was employed to lower the detection limits. The analysts were not aware of the identity of the recovered samples. The entire study (recruitment to data analysis) was performed in April and May of 2007. Six months after this study a second study was performed in which the same subjects rinsed with $912 \mu \mathrm{g} / \mathrm{g} \mathrm{F}(48 \mathrm{mmol} / \mathrm{l} \mathrm{NaF})$. The same subject protocol and analysis methods were employed.

\section{Statistical Procedures}

A significance level of $\mathrm{p}<0.05$ was used in all statistical tests which were performed using SigmaStat software (Systat Software, Inc., San Jose, Calif., USA,). The null hypothesis that there was no difference between the treatments was examined by a one-way repeated measures analysis of variance (ANOVA). However, because of the separation between treatments times, the 912 ppm F rinse was not included in the statistical analysis. In order to employ a parametric repeated measures analysis of variance, a logarithmic transformation of the salivary $F$ levels was required. The Holm-Sidak pairwise multiple comparison procedure was then used to examine the effects of the individual rinses. The standard error is used here as measures of the standard uncertainty.

\section{Results}

Unlike our previous 1-hour data on oral fluid F [Vogel et al., 2006a, b, 2008] both the salivary mass and salivary F data were normally distributed, hence the arithmetic average of these values is reported (table 1). No statisti-
Table 1. Mass and F concentrations (mean \pm SE) in saliva samples obtained overnight after use of a Ca lactate pre-rinse followed by a $228 \mu \mathrm{g} / \mathrm{g}$ F rinse, a 228 or $912 \mu \mathrm{g} / \mathrm{g}$ F rinse alone (with no prerinse), or a distilled water rinse

\begin{tabular}{llll}
\hline Rinse & Subjects & $\begin{array}{l}\text { Salivary mass } \\
\text { g/min }\end{array}$ & $\begin{array}{l}\text { Saliva fluoride } \\
\mu \mathrm{mol} / \mathrm{l}\end{array}$ \\
\hline Ca rinse/228 $\mu \mathrm{g} / \mathrm{g}$ F rinse & 12 & $0.662 \pm 0.082$ & $11.0 \pm 1.9^{\mathrm{a}}$ \\
$228 \mu \mathrm{g} / \mathrm{g}$ F rinse & 12 & $0.730 \pm 0.079$ & $1.85 \pm 0.13^{\mathrm{b}}$ \\
Distilled water rinse & 12 & $0.748 \pm 0.069$ & $1.39 \pm 0.12^{\mathrm{b}}$ \\
$912 \mu \mathrm{g} / \mathrm{g}$ F rinse & 11 & $0.776 \pm 0.092$ & $4.6 \pm 1.1$ \\
\hline
\end{tabular}

For saliva F, means followed by different superscript letters have a statistically significant difference (Holm-Sidak pairwise multiple comparison test, $\mathrm{p}<0.05)$. The $912 \mu \mathrm{g} / \mathrm{g}$ F rinse data was obtained 6 months later and hence was not included in the statistical analysis.

${ }^{1}$ Data were obtained from centrifuged saliva.

cally significant differences were found in the salivary flow rates. There was no statistically significant difference between the water rinse and the $228 \mu \mathrm{g} / \mathrm{g}$ F rinse. The Ca pre-rinse induced a statistically significant increase in salivary F over the $228 \mu \mathrm{g} / \mathrm{g}$ F rinse (by $5.5 \times$; $\mathrm{p}<0.0002)$. The $912 \mu \mathrm{g} / \mathrm{g} \mathrm{F}$ rinse increased overnight salivary $\mathrm{F}$ relative to the water rinse or $228 \mu \mathrm{g} / \mathrm{g} F$ rinse by $3.3 \times$ and $2.5 \times$, respectively.

\section{Discussion}

The overnight salivary $F$ values after the water and 228 $\mu \mathrm{g} / \mathrm{g}$ F rinses found in this study are somewhat $(\approx 30 \%)$ lower than previous overnight values reported by us [Vogel et al., 1997], due most probably to the different subject population and the changes in analytical techniques noted above. It should be noted that, although our 1997 study found, as in the current study, no overnight increase in centrifuged salivary F after use of the $228 \mu \mathrm{g} / \mathrm{g}$ F rinse, a nearly $2 \times$ increase in whole (uncentrifuged) salivary $\mathrm{F}$ was observed. Whole saliva $\mathrm{F}$, which is often measured in studies of salivary F [Pessan et al., 2006], includes a large contribution from F-containing particles. However, free salivary F, which is similar to the F measured in centrifuged saliva, is the parameter related to the interaction of $\mathrm{F}$ with the tooth surface or plaque.

Soft tissue F reservoirs appear to be the source of saliva F after use of topical F agents [Jacobson et al., 1992; Zero et al., 1992]. Given the central role ascribed to 
Ca-mediated $\mathrm{F}$ reservoirs in maintaining oral fluid $\mathrm{F}$ [Arends and Christoffersen, 1990; Rølla and Saxegaard, 1990; Rose et al., 1996], the 6 times increase in overnight salivary F observed in this study, relative to a $228 \mu \mathrm{g} / \mathrm{g} \mathrm{F}$ rinse, can be ascribed to an increased formation of soft tissue 'Ca-F' reservoirs as a result of the use of the Ca prerinse. A study with Brazilian schoolchildren (noted above) [Pessan et al., 2006] found an increase in $1 \mathrm{~h}$ whole saliva $\mathrm{F}$ when a Ca pre-rinse was used with a $\mathrm{F}$ dentifrice compared to the $\mathrm{F}$ dentifrice alone, but no increase in overnight $\mathrm{F}$ levels. The different results of the dentifrice and aqueous rinse studies, which we have also observed in short-term (1 h) studies [Vogel et al., 2006b], suggest that Ca-binding agents found in dentifrices, in particular the surfactant sodium lauryl sulfate [Pessan et al., 2006; Vogel et al., 2006b], may be precipitating some of the additional Ca deposited in the oral tissue by the pre-rinse. Alternatively, the use of a post-dentifrice water rinse may have extracted some of the additional $\mathrm{Ca}-\mathrm{F}$ reservoirs before they have time to become fixed in the oral tissue.

The results reported here (table 1) demonstrate that the 6-9 times increases in salivary F previously reported [Vogel et al., 2006a, b] with the use of a Ca pre-rinse/ $\mathrm{NaF}$ rinse are persistent overnight. The difference between the results of using a Ca pre-rinse with an aqueous $\mathrm{F}$ rinse, and those obtained using the Ca pre-rinse with a $\mathrm{F}$ dentifrice, suggests that if these techniques are to be used as part of a tooth-brushing regimen, $\mathrm{F}$ dentifrices may need to be reformulated to reduce the concentration of $\mathrm{Ca}$ binding surfactants. Alternatively, the method of $\mathrm{Ca}$ and $\mathrm{F}$ application could be altered. As an example of the former approach the non-Ca-binding surfactant Tauranol (Fintex, Lakewood Park, N.J., USA), which has been tested as an antiplaque agent [Nabi et al., 1996], could be substituted for sodium lauryl sulfate. A particularly attractive example of the latter approach, which also obviates the danger of water-rinse extraction of the $\mathrm{Ca}-\mathrm{F}$ reservoirs noted above, is the use of a Ca dentifrice with an aqueous $\mathrm{F}$ rinse (in place of the usual water rinse). This method of $\mathrm{Ca}$ and $\mathrm{F}$ application in conjunction with tooth brushing was also shown to produce high levels of salivary $\mathrm{F}$ [Vogel et al., 2006b].

Finally, it may be questioned if the overnight increase in salivary $\mathrm{F}$ found in this study could be expected to induce an increased cariostatic effect. (1) The previous 12hour study (noted above) [Vogel et al., 1997] also examined a Ca-containing experimental $\mathrm{F}$ rinse based on sodium hexafluorosilicate that has been shown to produce a very large increase in remineralization [Chow et al., $2000,2002]$ in an in situ model. Given that such models, if properly designed, have been described as 'predictors of clinical efficacy' [Stookey et al., 1992], it is noteworthy that the increase in $12 \mathrm{~h}$ salivary $\mathrm{F}$ from the previously tested rinse was only about $20 \%$ of the increase observed in the current study. (2) Plaque fluid, rather than saliva, is the oral fluid that is most relevant to the de- and remineralization process associated with caries. A reexamination of the data [unpubl. data] of the previous overnight study noted above [Vogel et al., 1997] revealed, in agreement with a 2-hour study [Vogel et al., 1992], that there is statistically significant correlation between centrifuged salivary $\mathrm{F}$ and plaque fluid $\mathrm{F}$ concentration. (3) The Ca pre-rinse $/ 228 \mu \mathrm{g} / \mathrm{g}$ F produced a $\approx 2.5$ times higher centrifuged salivary $\mathrm{F}$ than the $912 \mu \mathrm{g} / \mathrm{g}$ F rinse, although the latter rinse has 4 times more F (table 1). The apparent correlation between salivary $\mathrm{F}$ and plaque fluid F noted above (at least for post-rinse times $\geq 2 \mathrm{~h}$ ), and the theoretical relationship of the latter quantity to the cariostatic effect of this ion [Vogel et al., 2008; Yamazaki et al., 2007] then suggests that the potential increase in cariostatic effect with a Ca pre-rinse/F rinse would be greater than that found on going from a conventional dentifrice to one with a considerably high F content. (4) Several studies in fact have concluded that such high-strength dentifrices do confer an additional cariostatic effect [Bartizek et al., 2001; Biesbrock et al., 2003; Tavss et al., 2003; Stookey et al., 2004]. Thus, although the true value of Ca pre-application procedure will need to be assessed in a clinical trial, the data presented here suggest that this methodology has the potential to produce an enhanced cariostatic effect without increasing the amount of applied F.

\section{Acknowledgement}

This study was supported by a grant from the American Dental Association Foundation and by USPHS Research DE14707 to the American Dental Association Foundation from the National Institutes of Health - National Institute of Dental and Craniofacial Research, and is part of the dental research program conducted by the National Institute of Standards and Technology in cooperation with the American Dental Association Foundation. 


\section{References}

Arends J, Christoffersen J: Nature and role of loosely bound fluoride in dental caries. J Dent Res 1990;69:601-605.

- Bartizek RD, Gerlach RW, Faller RV, Jacobs SA, Bollmer BW, Biesbrock AR: Reduction in dental caries with four concentrations of sodium fluoride in a dentifrice: a meta-analysis evaluation. J Clin Dent 2001;12:57-62.

- Biesbrock AR, Bartizek RD, Gerlach RW, Jacobs SA, Archila L: Dose response efficacy of sodium fluoride dentifrice at 9 and 21 months with supervised brushing. Am J Dent 2003; 16:305-312.

-Chow LC, Takagi S, Carey CM, Sieck BA: Remineralization effect of a two-solution fluoride mouth rinse - an in situ study. J Dent Res 2000;79:991-995.

-Chow LC, Takagi S, Frukhtbeyn S, Sieck BA, Parry EE, Liao NS, Schumacher GE, Markovic M: Remineralization effect of a lowconcentration fluoride rinse in an intraoral model. Caries Res 2002;36:136-141.

Featherstone JD: The science and practice of caries prevention. J Am Dent Assoc 2000;131: 887-899.

-Jacobson AP, Stephen KW, Strang R: Fluoride uptake and clearance from the buccal mucosa following mouthrinsing. Caries Res 1992;26:56-58.

-Margolis HC, Moreno EC: Physicochemical perspectives on the cariostatic mechanisms of systemic and topical fluorides. J Dent Res 1990;69:606-613.
Nabi N, Kashuba B, Lucchesi S, Afflitto J, Furuichi $Y$, Gaffar A: In vitro and in vivo studies on salifluor/PVM/MA copolymer/NaF combination as an antiplaque agent. J Clin Periodontol 1996;23:1084-1092.

- Pessan JP, Sicca CM, de Souza TS, da Silva SM, Whitford GM, Buzalaf MA: Fluoride concentrations in dental plaque and saliva after the use of a fluoride dentifrice preceded by a calcium lactate rinse. Eur J Oral Sci 2006; 114:489-493.

Rølla G, Saxegaard E: Critical evaluation of the composition and use of topical fluorides with emphasis on the role of calcium fluoride in caries inhibition. J Dent Res 1990;69:780785.

Rose RK, Shellis RP, Lee AR: The role of cation bridging in microbial fluoride binding. Caries Res 1996;30:458-464.

-Stookey GK, Katz BP, Beiswanger BB, Dunipace AJ: Sample size considerations in designing studies with intra-oral models. J Dent Res 1992;71:819-821.

-Stookey GK, Mau MS, Isaacs RL, GonzalezGierbolini C, Bartizek RD, Biesbrock AR: The relative anticaries effectiveness of three fluoride-containing dentifrices in Puerto Rico. Caries Res 2004;38:542-550.

-Tavss EA, Mellberg JR, Joziak M, Gambogi RJ, Fisher SW: Relationship between dentifrice fluoride concentration and clinical caries reduction. Am J Dent 2003;16:369-374.

Ten Cate JM: In vitro studies on the effects of fluoride on de- and remineralization. J Dent Res 1990;69:614-619.

-Vogel GL, Carey CM, Chow LC, Ekstrand J: Fluoride analysis in nanoliter- and microlitersize fluid samples. J Dent Res 1990;69:522528.
Vogel GL, Chow LC, Carey CM, Schumacher GE, Takagi S: Effect of a calcium pre-rinse on salivary fluoride after a 228-ppm fluoride rinse. Caries Res 2006a;40:178-180.

-Vogel GL, Mao Y, Carey CM, Chow LC, Takagi $S$ : In vivo fluoride concentrations measured for two hours after a $\mathrm{NaF}$ or a novel two-solution rinse. J Dent Res 1992;71:448-452.

-Vogel GL, Mao Y, Carey CM, Chow LC, Takagi $S$ : Increased overnight fluoride concentrations in saliva, plaque, and plaque fluoride after a novel two-solution rinse. J Dent Res 1997;76:761-767.

-Vogel GL, Schumacher GE, Chow LC, Takagi S, Carey CM: Ca pre-rinse greatly increases plaque and plaque fluid F. J Dent Res 2008; 87:466-469.

Vogel GL, Shim D, Schumacher GE, Carey CM, Chow LC, Takagi S: Salivary fluoride from fluoride dentifrices or rinses after use of a calcium pre-rinse or calcium dentifrice. Caries Res 2006b;40:449-454.

-Yamazaki H, Litman A, Margolis HC: Effect of fluoride on artificial caries lesion progression and repair in human enamel: regulation of mineral deposition and dissolution under in vivo-like conditions. Arch Oral Biol 2007; 52:110-120

-Zero DT, Raubertas RF, Pedersen AM, Fu J, Hayes AL, Featherstone JDB: Studies of fluoride retention by oral soft tissues after the application of home-use topical fluorides. J Dent Res 1992;71:1546-1552. 